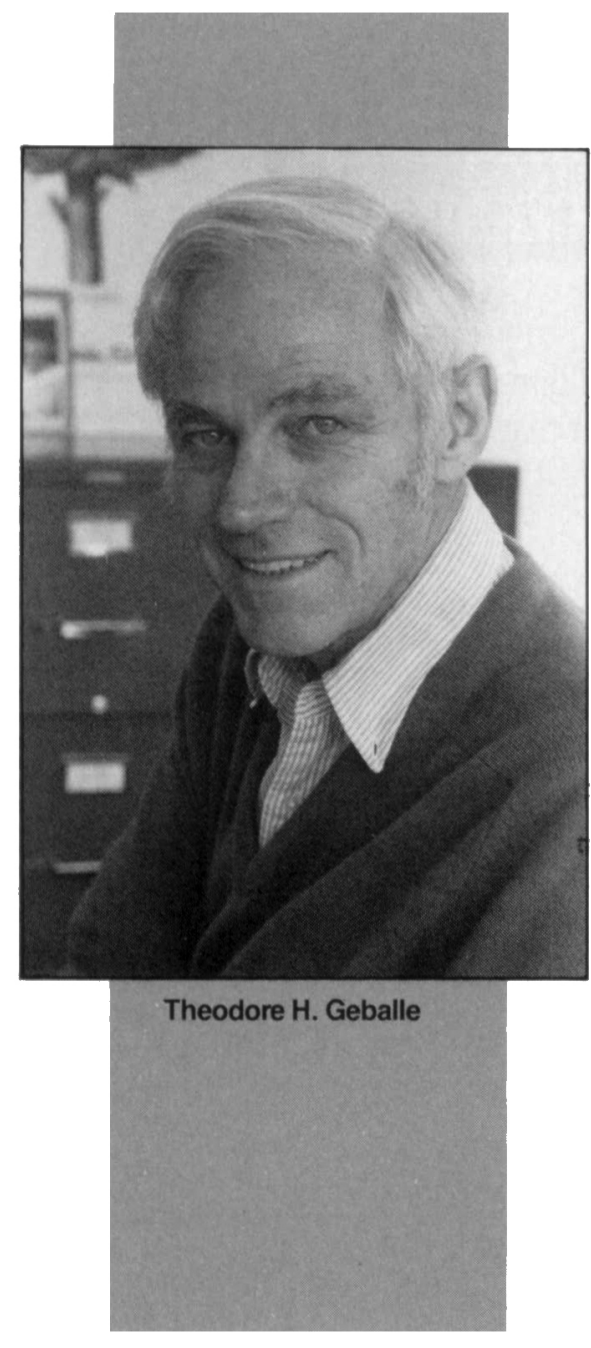

Theodore H. Geballe has been selected as the recipient of the 1991 Von Hippel Award of the Materials Research Society "in recognition of his ingenious use of chemical principles to synthesize novel materials of technological importance, his careful experiments on a wide range of materials to illuminate fundamental materials properties and behavior, and his leadership in helping to formulate the modern concepts of materials science through his consistent and strong emphasis on interdisciplinarity as a scientist, teacher, and administrator."

Geballe has been devoted to the synthesis of new materials in areas of potential technological significance and to understanding novel physical properties, particularly in the areas of semiconduction and superconduction. He has effectively combined disciplines of chemistry and physics and helped shape the evolution of materials science.

He has patiently insisted that the synthesis of new materials, the determination

\title{
Geballe Receives Von Hippel Award
}

\begin{abstract}
"In recognition of his ingenious use of chemical principles to synthesize novel materials of technological importance, his careful experiments on a wide range of materials to illuminate fundamental materials properties and behavior, and his leadership in helping to formulate the modern concepts of materials science through his consistent and strong emphasis on interdisciplinarity as a scientist, teacher, and administrator."
\end{abstract}

of their physical properties and the theoretical interpretation of these properties are most effectively done as part of a continuous "feedback loop," not separately. Based on this point of view, he established a school of materials physics within the Department of Applied Physics at Stanford University. This school is regarded by many as a model of multidisciplinary research. He has been an effective teacher of solid-state physics for over 20 years and has produced a series of outstanding graduate students who truly understand and practice interdisciplinary materials research.

Geballe's early work in the 1950s centered on transport in semiconductors (Ge and $\mathrm{Si}$ ). His work of this period on conduction, piezoresistance, phonon drag, thermal conduction, and impurity hopping conduction, is considered among the best ever done on these topics.

He is widely known for his many contributions to superconductivity. His work with Bernd T. Matthias on the A15 class of superconductors included discovering $\mathrm{Nb}_{3} \mathrm{Sn}$ superconducting at $18 \mathrm{~K}$, the record at the time. This material became of great technological importance for superconducting magnets. Later Geballe and Matthias raised the critical temperature to over $20 \mathrm{~K}$ with $\mathrm{Nb}_{3}$ (AlGe).

His work led to the development of a technologically important class of superconductors based on intercalated compounds (layered transition metal dichalcogenides). He demonstrated enormous critical field anisotropy, a forerunner of effects in recent high $\mathrm{T}_{\mathrm{c}}$ superconductors. At Stanford, his group was the first to produce thin films of the high $T_{c}$ materials, producing them within a few weeks of the discovery of the $90 \mathrm{~K}$ phases.

Geballe has further exhibited his quiet but effective leadership as director of Stanford's Center for Materials Research and by serving on many national committees, in- cluding the President's Commission on Superconductivity. This committee was set up by former President Reagan to advise the administration on policies regarding the new high-temperature superconductors

Geballe received a BS in chemistry and a $\mathrm{PhD}$ in physical chemistry from the University of California, Berkeley. In 1952 he joined the technical staff of Bell Telephone Laboratories in Murray Hill, New Jersey, and became head of the department of low-temperature and solid-state physics in the physical research laboratory in 1957. In 1967 he became a professor at Stanford University and is currently an emeritus professor in the Departments of Applied Physics and Materials Science and Engineering.

In 1970 Geballe, together with Bernd T. Matthias, received the Oliver E. Buckley Prize given by the American Physical Society. In 1975 he was the Guggenheim Fellow at Cavendish Laboratory, Cambridge, England. In 1978 he was named Theodore and Sydney Rosenberg Professor of Applied Physics at Stanford University. In 1989 he was the recipient of the first Bernd T. Matthias Memorial Award of the International Conference on the Materials and Mechanisms of Superconductivity.

Geballe is a Fellow of the American Physical Society, and a member of the $\mathrm{Na}$ tional Academy of Sciences, American Academy of Arts and Sciences, American Chemical Society, and the Materials Research Society.

The Von Hippel Award, the Materials Research Society's highest honor, recognizes originality of intellect, combined with vision that transcends the boundaries of conventional scientific disciplines. The award will be presented to Geballe on Wednesday, December 4 at 6:00 p.m. in the Marriott Hotel during the 1991 MRS Fall Meeting in Boston. Following the award presentation, Geballe will give a lecture highlighting his research. 